\title{
Quantification of gas emissions from stored softwood chips as solid biofuels
}

\author{
X. He • A. K. Lau $\cdot$ S. Sokhansanj • \\ C. J. Lim $\cdot$ X. T. Bi $\cdot$ S. Melin
}

Received: 3 April 2013/Revised: 5 January 2014/Accepted: 5 March 2014/Published online: 19 March 2014

(C) Islamic Azad University (IAU) 2014

\begin{abstract}
Western Red Cedar (WRC) is one of the abundant softwood species, which is considered as a good source of biofuel. This paper aims at quantifying gas emissions from stored WRC woodchips and studying the potential health impact during storage and transportation. Experiments were conducted using lab-scale reactors for a range of temperatures under both non-aerobic and aerobic conditions depending on oxygen level. Results from tests using non-aerobic reactors showed that the highest carbon dioxide emission factor of $2.8 \mathrm{~g} / \mathrm{kg}$ dry matter (DM) was observed at $20^{\circ} \mathrm{C}$ for a storage period of 2 months. Although the carbon monoxide emission factor was much lower at $0.03 \mathrm{~g} / \mathrm{kg} \mathrm{DM}$, it increased with increasing temperatures due to chemical oxidation. Carbon dioxide and carbon monoxide emissions from the aerobic reactors exhibited similar trends as the non-aerobic reactors with respect to the effect of temperature. Total gas emissions were higher from the aerobic reactors compared with those from non-aerobic reactors. Results from the qualitative gas chromatography-mass spectrometry analysis indicated a range of volatile organic compounds was emitted from the stored WRC woodchips. Some of these volatile organic compounds might be associated with the characteristic
\end{abstract}

X. He · A. K. Lau ( $₫)$ · S. Sokhansanj · C. J. Lim · X. T. Bi Department of Chemical and Biological Engineering, University of British Columbia, 2360 East Mall, Vancouver, BC V6T 1Z3, Canada

e-mail: aklau@chbe.ubc.ca

\section{S. Sokhansanj}

Environmental Sciences Division, Oak Ridge National

Laboratory, Oak Ridge, TN 37831, USA

S. Melin

Delta Research Corporation, 501 Centennial Parkway, Delta, BC V4L 2L5, Canada pungent smell of WRC which could cause odor nuisance to the neighboring community. The total volatile organic compounds concentration was found to be positively correlated with temperature. At the end of the storage period, percent DM loss was below $1 \%$ for both the non-aerobic and aerobic reactors, reaffirming the decay-resistance characteristics of WRC.

Keywords Gas chromatography analysis · Volatile organic compounds $\cdot$ Storage $\cdot$ Aerobic $\cdot$ Non-aerobic . Dry matter loss

\section{Introduction}

Due to the non-renewable nature of fossil fuels and their negative impacts on the environment, the utilization of alternative fuel to generate heat and power has become an important element of sustainability in today's world. Biomass has been increasingly used as biofuel due to its notable lower greenhouse gas emissions (GHG) and criteria air pollutant emissions as compared to fossil fuels, and its fewer regional restrictions as compared to other renewable energy sources such as wind and solar (Zhang et al. 2009). The development of bioenergy and biomaterials from sustainable biomass will lead to a new scene of industry (Ragauskas et al. 2006). In Canada, many clean energy projects have been put in place. A large amount of lignocellulosic biomass are converted to biofuels and integrated into the energy generation systems.

Gas emissions $\left[\mathrm{CO}_{2}, \mathrm{CO}, \mathrm{CH}_{4}\right.$ and volatile organic compounds (VOCs)] from woody biomass storage systems have been studied in recent years. Woody biomass emits considerable VOCs that are mainly terpene compounds (Leinonen and Tutkimuskeskus 2004). Svedberg et al. 
(2004) identified the emission of high levels of hexanal as a result of the general degradation processes of wood during the storage of wood pellets. Some of the major VOCs emitted from stored wood pellets including aldehydes are known to cause irritation to the respiratory system (Hagström 2008). VOCs are also generated during wood drying. Stahl et al. (2004) observed an increase in the total amount of VOCs, including the faster release of terpenes, with increased drying temperature. Granstrom and Mansson (2008) reported that formaldehyde, a common VOC produced during wood drying, is potentially carcinogenic aside from its short-term health effects such as eye and throat irritation, and suggested factors such as temperature and moisture content would affect the emissions from the materials. Arshadi et al. (2009) found that high temperatures used for drying sawdust subsequently led to higher emissions of aldehydes and ketones from pellets.

In terms of $\mathrm{CO}_{2}, \mathrm{CO}$ and $\mathrm{CH}_{4}$ emissions, Wihersaari (2005) concluded that the $\mathrm{CO}_{2}$ emissions from fresh forest residues were almost three times higher than the dried materials, and suggested that mixing the heaps during the storage period would probably cause increased emission rates. Rupar and Sanati (2005) investigated wood chip piles in an existing terminal storage and revealed that air emission increased when the temperature directly above the pile increased; also, more terpenes were released with a greater amount of precipitation. Other studies have found higher emission factors associated with higher temperatures, whereas increased relative humidity in the enclosed container increased the rate of gas emission and corresponding depletion in oxygen (Kuang et al. 2009a). In a lab-scale study of gas emission from stored fresh Douglas-fir residues by He et al. (2012), results showed that higher temperature led to higher gas concentrations and greater dry matter (DM) loss. The oxygen content was also found to be positively related to the emission rates of $\mathrm{CO}_{2}$ and $\mathrm{CO}$ from wood pellets (Kuang et al. 2009b).

Emissions of $\mathrm{CO}, \mathrm{CO}_{2}$ and $\mathrm{CH}_{4}$ are likely due to biodegradation and auto-oxidative reactions of organic constituents naturally present in wood (Kuang et al. 2008). $\mathrm{CO}_{2}$ can be generated from thermal oxidation, aerobic biodegradation or anaerobic biodegradation. Svedberg et al. (2004, 2008) and Arshadi and Gref (2005) postulated that $\mathrm{CO}$ is formed from the auto-oxidative degradation of lipids and fatty acids present in wood, and storage temperature is one of the critical factors. Hellebrand and Schade (2008) suggested that CO generation is independent of microbial activity in the feedstock, but it is promoted by increased temperatures and available oxygen. Moreover, CO produced from plant litter was most likely caused by thermochemical oxidation rather than a biological process. Some organic acids such as acetic acid are likely to be emitted from the breakdown of wood hemicelluloses (Johansson and Rasmuson 1998). The extractives in wood have also been realized as one source of VOCs; aromatic and ether extractives are released when temperature increases. Under low temperatures, the breakdown of polysaccharides and functional groups of hemicellulose and lignin result in the emission of methanol, light aldehydes, formic acid and acetic acid as the major substances (Koppmann et al. 2005).

Use of wood pellets and wood chips as solid biofuels are becoming more popular in some parts of the world. Western Red Cedar (WRC, Thuja plicata) is an abundant softwood species in British Columbia. The residues from WRC harvest can be used in the form of chips or pellets for combustion, or converted to liquid biofuels (Liu et al. 2010; Nakamura et al. 2010; Zhang et al. 2011). For instance, WRC chips are being considered as possible solid biofuel for a gasification plant that has been installed as part of a District Energy System on the University of British Columbia campus at Vancouver, BC, Canada. Other biomass feedstocks such as spruce-pine-fir residues and urban tree trimmings and wood waste may also be used.

Problems pertinent to the storage and transportation of high moisture wood chips include gas emissions, odors, DM loss and fire risk (Rentizelas et al. 2009). A large depletion in oxygen together with the $\mathrm{CO}_{2}$ and VOCs formation has been reported during the sea transportation of logs and wood chips in confined spaces (Svedberg et al. 2009). There have been a number of fatalities from offgassing or oxygen depletion in storage of wood pellets and chips (Svedberg et al. 2008; Gauthier et al. 2012). Potential emissions from storage and drying of WRC chips have therefore generated concerns about their utilization.

Based on the literature review, few studies can be found on the gas emissions from fresh biomass, and in particular WRC chips, under different storage conditions in terms of oxygen availability. WRC is known to have a higher content of extractives (around 10\%) than other wood species (for instance, Douglas fir $5.9 \%$ ) (Gonzalez 1997). There would be less energy available per tonne of material handled as a result of gas emissions and hence DM loss. WRC has a characteristic pungent smell which could cause odor nuisance to the neighboring community. Prolonged exposure to the emitted gases may be harmful to human health. Fatalities can occur when workers are exposed to oxygen depletion and hazardous gas emissions due to the storage of these materials in enclosed space with little or no ventilation.

The objective of this study is to quantify gas emissions from stored biomass pertinent to WRC and the effect on DM loss with respect to temperature and oxygen content. Experiment was conducted during the period February- 
May 2012 at the University of British Columbia, Vancouver, BC, Canada. Findings from this study would provide the data required for assessing the potential impact of the gas emissions on the environment and human health. This could assist in the better handling and management of fresh biomass prior to their utilization in different energy production processes.

\section{Materials and methods}

Materials

In North America, WRC grows at low-to-mid elevations along the Pacific coast stretching from northern California (lat. $\sim 40^{\circ} \mathrm{N}$ ) to southeastern Alaska (lat. $\sim 56^{\circ} \mathrm{N}$ ). It is among the most widespread trees in the Pacific Northwest including the province of British Columbia. The red cedar materials used in this study originated from Vancouver Island (lat. $\sim 49^{\circ} \mathrm{N}$ ) with moist and mild-to-cool climate conditions. Subsequently, the logs are stored and transported in water booms and tug-boated to sawmills in the Lower Mainland Vancouver area. The residual chips are created from waste wood which is cut off to make the appropriately sized products for sale as boards, siding and fencing. They are taken from a chipper, which chips and screens the chips for fines and oversized pieces, leaving a uniform chip for pulp or for bioenergy applications.

Fresh WRC chips as shown in Fig. 1 were obtained from a recycling yard in Langley, BC. We received approximately $30 \mathrm{~kg}$ of chips. The chips were stored in a cold room at $4{ }^{\circ} \mathrm{C}$ at the UBC laboratory. The chips were picked up 1 week after chipping operation was done at the recycling yard (supplier's site); debris was separated from the chips during the screening process at the recycling yard; no barks were present in the materials. The chip shape was rhombus. The chips had an average size of $10-20 \mathrm{~mm}$, as measured by the Gilson Testing Screens TS- 1 and TS-2

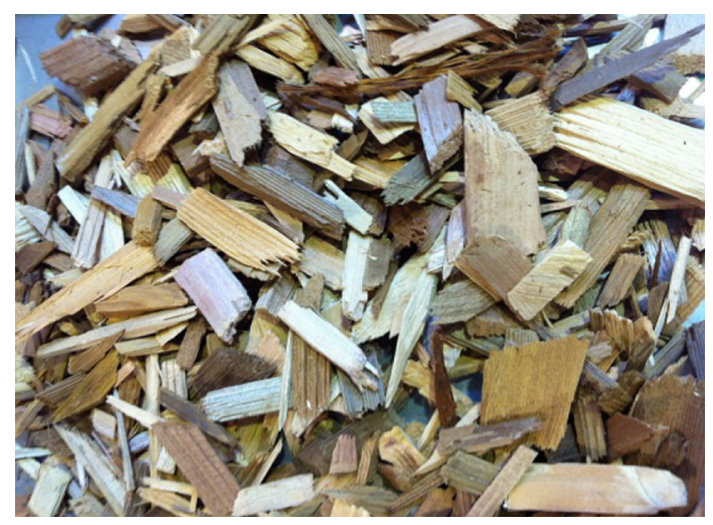

Fig. 1 Western Red Cedar chips as received from the recycling yard
(Gilson Company, Worthington, Ohio). The average ash content and calorific value of the chips were measured to be $0.38 \%$ and $19.1 \mathrm{MJ} / \mathrm{kg}$, respectively. Moisture content of the samples was determined in triplicate in a forced-air convection oven at $103{ }^{\circ} \mathrm{C}$ for $24 \mathrm{~h}$ according to ASABE Standards S358.2(ASABE 2010). Initial moisture content of the chips was around $50 \%$ (wet mass basis). A number of glass containers (2L) were fitted with valves and sampling ports and assembled. Each glass container (reactor) was loosely loaded with $330 \mathrm{~g}$ wood chips.

Experimental setup

Two series of tests were conducted in order to simulate the storage environment, one under aerobic and the other under non-aerobic conditions. The materials in a pile experience different environmental conditions depending on the availability of oxygen. Biomass in the outer layers of pile close to the surface may be assumed to be more aerobic due to adequate oxygen supply from the air. However, at a certain depth from the surface, it may be subject to nonaerobic conditions after a period of time because of oxygen deficiency. In the literature, oxygen concentrations lower than $2 \%$ were observed below a depth of 0.5 and $1.5 \mathrm{~m}$ inside two stockpiles of biomass waste (softwood and hardwood barks) (Biomass Technology Group BV 2002). The depletion rate of oxygen in a pile depends on the materials and their physical and chemical characteristics. At the extreme, the inner core of the pile may even

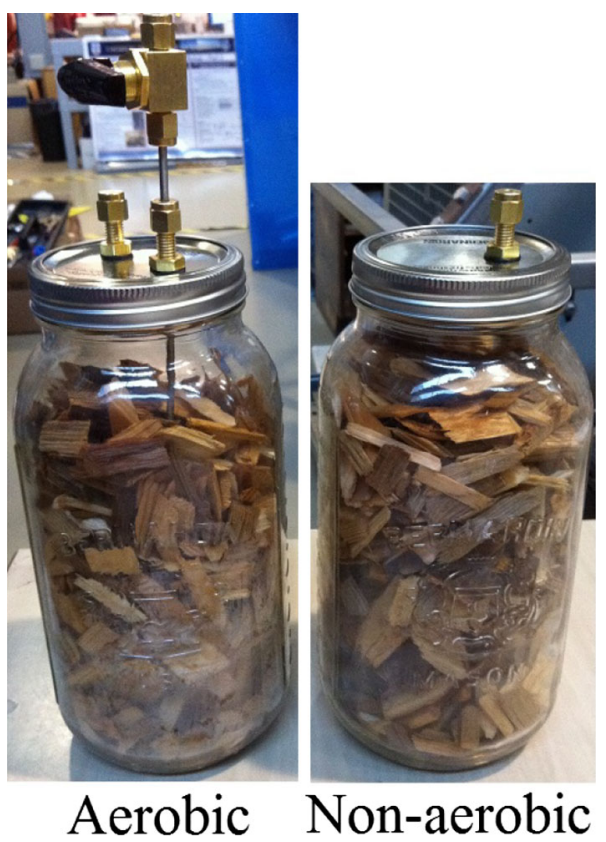

Fig. 2 Left reactors for aerobic tests were ventilated every $24 \mathrm{~h}$ during the experiment. Right reactors for non-aerobic tests remain sealed for the duration of the experiment 
experience anaerobic condition due to a complete lack of oxygen.

Ten reactors were divided into two equal groups. As shown in Fig. 2, non-aerobic reactors were sealed at all times to study gas emission under airtight (non-aerobic) conditions. Air was pumped into the aerobic reactors at a flow rate of $0.025 \mathrm{~m}^{3} / \mathrm{h}$ for $10 \mathrm{~min}$ after the daily gas sampling event, in order to replenish and maintain a high oxygen level (aerobic condition) in the reactors. After the reactors were loaded with the materials, they were sealed and placed under different temperatures based on the experimental design. Some reactors were placed in a cooler at $5{ }^{\circ} \mathrm{C}$ for the test conducted under this temperature. Similarly, other reactors were placed in ovens with temperature maintained at $20,35,45$ and $50{ }^{\circ} \mathrm{C}$ for tests performed under this range of temperature. The range of temperature adopted for the test represents cool-to-hot climate conditions in different geographic locations, and involving seasonal variations. Two replicates were performed for each test. In all cases, the study period is approximately 2 months.

\section{Gas emission measurements}

The concentrations of $\mathrm{CO}_{2}, \mathrm{CO}$ and $\mathrm{CH}_{4}$ along with $\mathrm{O}_{2}$ were analyzed by gas chromatography GC (Model SRI 8610C, Mandel, USA). The GC was calibrated regularly with the corresponding standard gases. A GC/MS analyzer (Model 5975B/6890 N, Agilent Technologies, USA) was used for qualitative analysis of the VOCs. During each sampling event, gas sample was drawn from each reactor to measure $\mathrm{CO}_{2}, \mathrm{CO}, \mathrm{CH}_{4}$ and $\mathrm{O}_{2}$ concentrations. For the aerobic reactors, gas emissions from the reactors were measured once a day. Gas sampling using syringe was done within 1-2 min. Gas emissions from the non-aerobic reactors were measured daily at the beginning of the test, and then every few days in the later stage of the experiment. $250 \mu \mathrm{L}$ gas sample was drawn from each reactor to analyze the VOC composition.

For the aerobic reactors, the total concentration of VOCs (TVOC) was measured by a portable VOC monitor (Model PGM-7240, RAE Systems, San Jose, CA) on a daily basis. For the reactors under non-aerobic conditions, we could not use the same procedure since this would cause a larger amount of gases to be released from the reactor, thus affecting the accuracy of gas analysis for the remaining test (storage) period. Hence, TVOC for non-aerobic containers was measured at the end of the test period.

\section{Microbial analysis}

At the end of all tests, chip samples were taken from each reactor and sent to an ISO-certified microbiology laboratory (I.G. MicroMed Environmental, Vancouver, $\mathrm{BC})$ for cultivation and microbial analysis. Analysis of the samples started within $24 \mathrm{~h}$ of delivery. The duration of the microbial analysis procedure performed under both aerobic and anaerobic conditions was $48 \mathrm{~h}$. The methodology used for total bacterial counts (TBC) followed the MFHPB-18 Standard (Health Canada 2001); and enumeration of molds (fungi) in the samples was performed using MFHPB-22 Standard (Health Canada 2004). The threshold for bacteria and fungi detection in the samples was $5 \mathrm{cfu} / \mathrm{g}$.

\section{Data analysis}

In this study, the emissions of $\mathrm{CO}_{2}$ and $\mathrm{CO}$ are expressed as emission factors, in units of gram gas species per kilogram DM. The measured gas concentrations were converted from percent volumetric to emission factors by using the $\mathrm{N}_{2}$ balance method (Kuang et al. 2009a, b), assuming that nitrogen was not consumed during the test period. At constant temperature and pressure, the emission factor $f$ in $\mathrm{g} / \mathrm{kg} \mathrm{DM}$ is related to volumetric gas concentration $C_{i}$ as follows:

$f_{\mathrm{i}}=\frac{P C_{\mathrm{i}} V M_{\mathrm{wt}} C_{\mathrm{n} 0}}{R T M C_{\mathrm{nt}}}$.

where $i$ is the gas species, $P$ is absolute pressure of gas in the container $(\mathrm{Pa}), C_{i}$ is volumetric concentration of a particular gas $\left(\mathrm{m}^{3}\right.$ of gas species per $\mathrm{m}^{3}$ of gas going through the GC), $V$ is gas volume in the reactor $\left(\mathrm{m}^{3}\right), M_{\mathrm{wt}}$ is gas molecular weight $(\mathrm{g} / \mathrm{mol}), C_{\mathrm{n} 0}$ is initial concentration of nitrogen $(\%), C_{\mathrm{nt}}$ is the concentration of nitrogen at time $\mathrm{t}(\%), R$ is universal gas constant $(8.31 \mathrm{~J} / \mathrm{mol} . \mathrm{K}), T$ is temperature $(\mathrm{K})$ and $M$ is the total mass of materials in the container $(\mathrm{kg})$. The gas volume is the numeric difference between the volume of container and volume of chips. Change in pressure during the whole test was assumed to be minimal in general. The derivation of Eq. (1) is shown in the "Appendix".

\section{Results and discussion}

\section{Gas emissions}

\section{Non-aerobic conditions}

Results from the non-aerobic reactors in terms of emission factors are shown in Fig. 3. For each temperature, the $\mathrm{CO}_{2}$ emission factor $\left(f_{\mathrm{CO}_{2}}\right)$ increased gradually due to the accumulation of $\mathrm{CO}_{2}$ with time. It is evident that the emission factors were the highest at $20^{\circ} \mathrm{C}$ followed by $35^{\circ} \mathrm{C}$, but the emission factors were substantially reduced at temperatures of 45 and $50{ }^{\circ} \mathrm{C}$. The $\mathrm{CO}_{2}$ emission factor was 
(a)

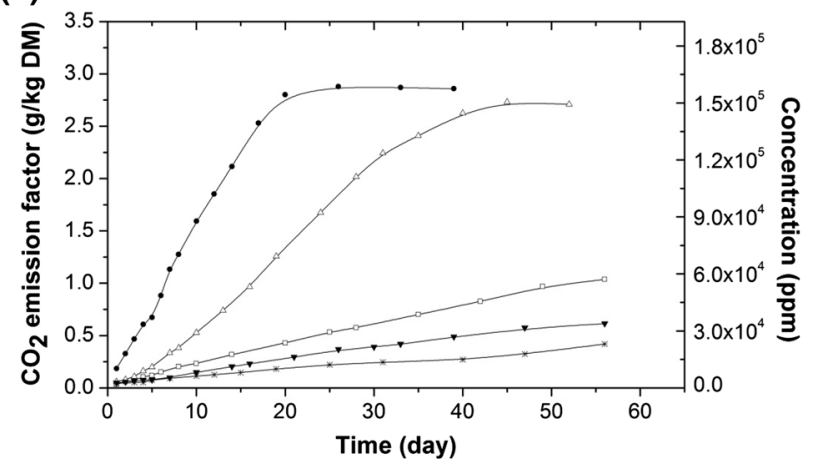

(b)
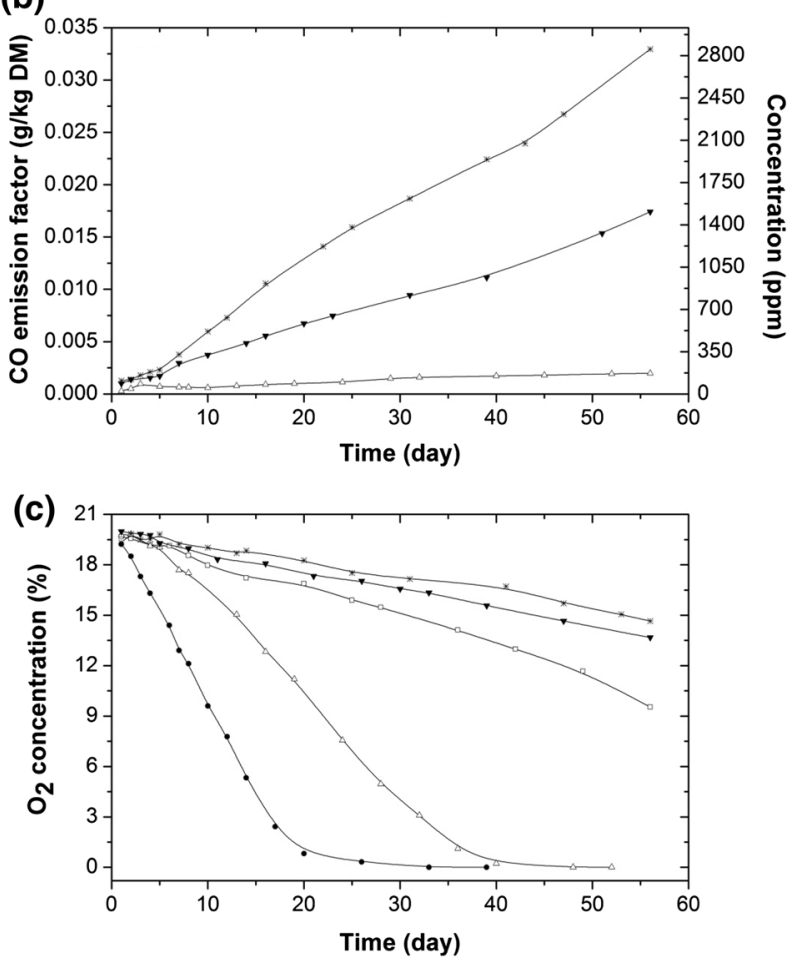

Fig. 3 Gas emission profiles from stored WRC chips under different temperatures (non-aerobic) (square $5{ }^{\circ} \mathrm{C}$; circle $20^{\circ} \mathrm{C}$; triangle $35{ }^{\circ} \mathrm{C}$; inverted triangle $45^{\circ} \mathrm{C}$; asterick $50{ }^{\circ} \mathrm{C}$ )

also lower at $5{ }^{\circ} \mathrm{C}$. The trends of the $\mathrm{CO}_{2}$ profiles were exactly opposite to the $\mathrm{O}_{2}$ profiles for all temperatures. After about 3 weeks, $f_{\mathrm{co}_{2}}$ from the $20{ }^{\circ} \mathrm{C}$ reactor reached a plateau of $2.8 \mathrm{~g} / \mathrm{kg} \mathrm{DM}$ as oxygen content was depleted to nearly $0 \%$. This value corresponded to a $\mathrm{CO}_{2}$ concentration of $16 \%$ (on volumetric basis). For the $35{ }^{\circ} \mathrm{C}$ reactor, $f_{\mathrm{CO}_{2}}$ increased to an asymptotic value of $2.7 \mathrm{~g} / \mathrm{kg}$ DM after 45 days storage. By comparison, $f_{\mathrm{co}_{2}}$ increased slowly at 5, 45 and $50{ }^{\circ} \mathrm{C}$, reaching only $1.1,0.6$ and $0.4 \mathrm{~g} / \mathrm{kg} \mathrm{DM}$ (or, $\mathrm{CO}_{2}$ concentration 2-7\%), respectively, after 60 days storage, implying that $\mathrm{CO}_{2}$ generation might be dominated by biological mechanism rather than chemical mechanism.

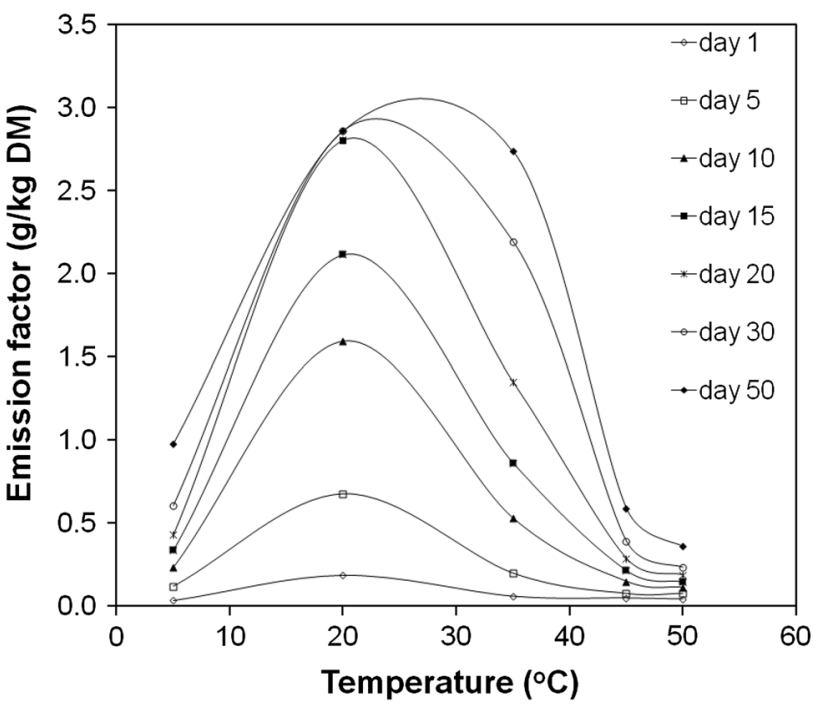

Fig. 4 Effect of temperature on $\mathrm{CO}_{2}$ emission factors during the testing period under non-aerobic conditions

Based on the $\mathrm{CO}_{2}$ emission data (Fig. 3a), the effect of temperature on $\mathrm{CO}_{2}$ emission factors was analyzed and plotted in Fig. 4. The quadratic polynomial $\left(f=a T^{2}+b T+c\right)$ was found to fit well to the data recorded at storage times beyond day 5 . The coefficients $(a, b, c)$ have different values for each curve at different times in Fig. 4. Again, it shows that $f_{\mathrm{CO}_{2}}$ is the highest at $20^{\circ} \mathrm{C}$, supporting the postulation that the generation of $\mathrm{CO}_{2}$ was dominated by biological mechanism rather than chemical mechanism.

$\mathrm{CO}$ was only observed to emit from the 35,45 and $50{ }^{\circ} \mathrm{C}$ reactors (Fig. 3b). For each temperature, the $\mathrm{CO}$ emission factor $f_{C O}$ increased gradually with time, though it is two orders of magnitude less than the $\mathrm{CO}_{2}$ emission factor. Furthermore, $f_{C O}$ increased significantly with temperature, being $0.033 \mathrm{~g} / \mathrm{kg} \mathrm{DM}$ at $50{ }^{\circ} \mathrm{C}$ versus $0.002 \mathrm{~g} / \mathrm{kg}$ $\mathrm{DM}$ at $35^{\circ} \mathrm{C}$ at the end of storage, and this trend is opposite to that observed for $\mathrm{CO}_{2}$. In general, $\mathrm{CO}$ generation is due to the chemical oxidation of materials and is promoted by increased temperature and the availability of oxygen. Our observations supported this mechanism.

Biomass can be decomposed both chemically and biologically. When chemical oxidation is dominant, the emitted gases will generally increase with increasing temperature according to the Arrhenius kinetics relationship. Temperature is among the most important environmental factors that control biological processes, whereby responses to temperature can be categorized in terms of three cardinal temperatures, namely the base or minimum temperature, the optimum temperature and the maximum temperature. In the case of microbial ecology, at temper- 
ature lower or higher than the optimum, bacteria and fungi could become dormant or even killed (Agrios 2004).

\section{Aerobic conditions}

The cumulative gas emissions from aerobic reactors are shown in Fig. 5a and b. At each temperature, $\mathrm{CO}_{2}$ and $\mathrm{CO}$ emissions increased slowly with time while oxygen levels remained close to $20 \%$ during the entire test period (Fig. 5c). Daily pumping of air into the aerobic reactor was effective in keeping the $\mathrm{O}_{2}$ content relatively high and
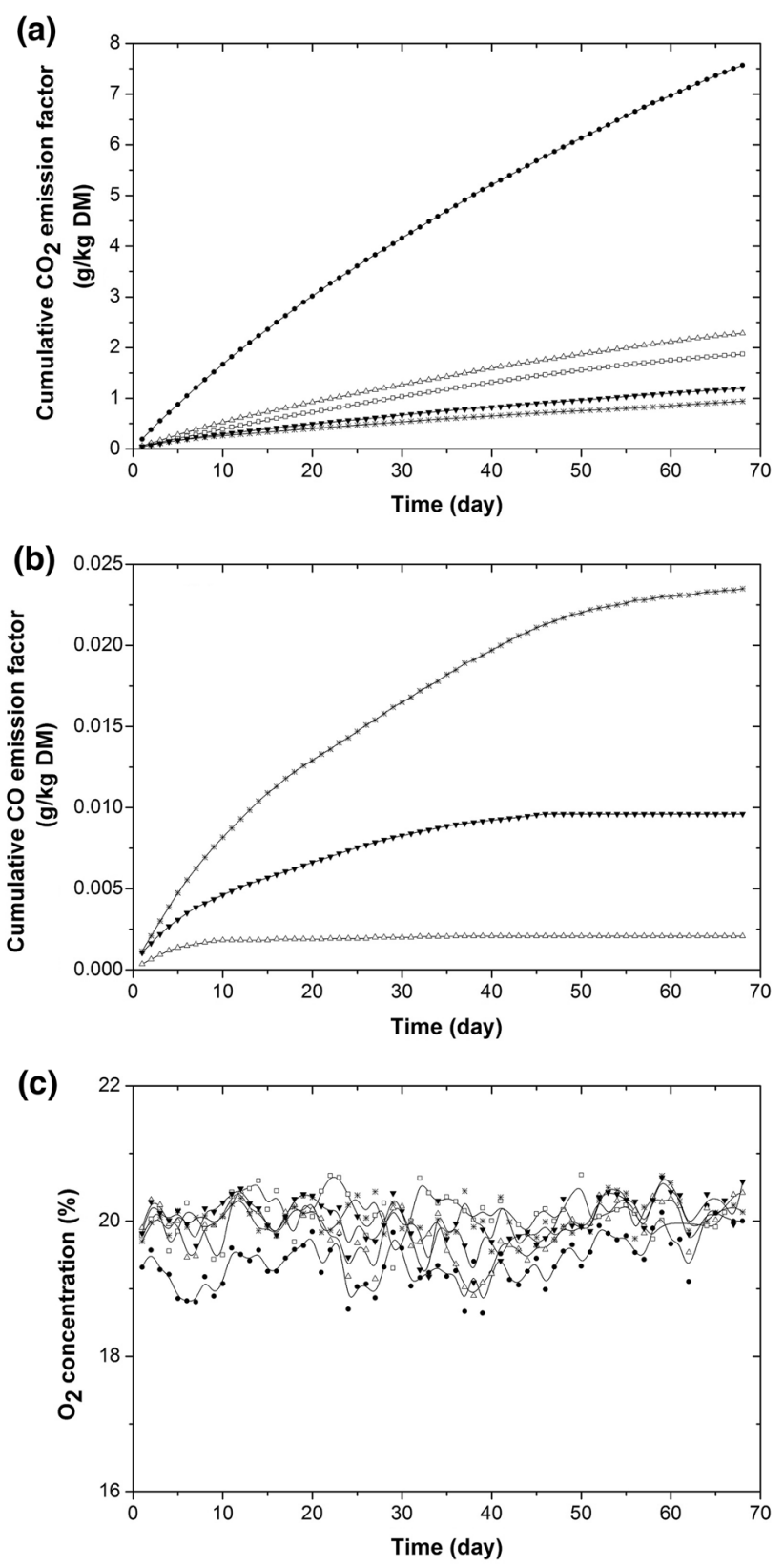

Fig. 5 Cumulative gas emissions from stored WRC chips under aerobic conditions (square $5{ }^{\circ} \mathrm{C}$; circle $20^{\circ} \mathrm{C}$; triangle $35^{\circ} \mathrm{C}$; inverted triangle $45^{\circ} \mathrm{C}$; asterick $50{ }^{\circ} \mathrm{C}$ ) constant. In terms of temperature effect, aerobic reactors displayed similar trends to anaerobic reactors. The peak $\mathrm{CO}_{2}$ emission factor was again observed at $20{ }^{\circ} \mathrm{C}$ which indicated biological process might contribute primarily to the emission. Depending on the temperature, the emission factors increased with time at different rates. The total $\mathrm{CO}_{2}$ emissions from aerobic reactors ranged from 1.0 to $7.5 \mathrm{~g} / \mathrm{kg}$ DM after the entire storage period depending on temperature. $\mathrm{CO}$ was only observed to emit from the 35,45 and $50{ }^{\circ} \mathrm{C}$ reactors (Fig. 5b). The $\mathrm{CO}$ emission factor experienced the same trend as the $\mathrm{CO}_{2}$ emission factor, but it had a positive relationship with temperature.

By comparison of Fig. 5 with Fig. 3, the total $\mathrm{CO}_{2}$ produced during storage was higher for the aerobic reactors. Over a storage period of 55 days, the highest total $\mathrm{CO}_{2}$ emission from the non-aerobic reactors and the aerobic reactors was 2.8 and $6.6 \mathrm{~g} / \mathrm{kg} \mathrm{DM}$, respectively, for the $20{ }^{\circ} \mathrm{C}$ temperature. The $\mathrm{CO}$ emissions from both conditions were similar. The difference between the $\mathrm{CO}_{2}$ emissions from non-aerobic and aerobic conditions is essentially due to oxygen content. As oxygen content was depleted to zero at $20{ }^{\circ} \mathrm{C}$ (Fig. 3c), the $\mathrm{CO}_{2}$ emission reached a plateau and did not increase further. In contrast, $\mathrm{CO}_{2}$ was produced continuously in the aerobic reactors with oxygen level almost close to ambient (Fig. 5c).

Microbial analysis results revealed that the TBC for the wood chip samples obtained from the aerobic reactors at the end of the tests were $(3,000,10,000,4,500$ and $30 \mathrm{cfu} / \mathrm{g}$ sample), whereas fungi counts were $(25,60,10$ and $<5 \mathrm{cfu} / \mathrm{g}$ sample) at $\left(5,20,35\right.$ and $\left.50{ }^{\circ} \mathrm{C}\right)$, respectively. The highest microbial activity was therefore in-line with the highest $\mathrm{CO}_{2}$ emission at $20^{\circ} \mathrm{C}$. In contrast, TBC were substantially lower for the wood chip samples obtained from the nonaerobic reactors at the end of the tests, being $(90,140,20$ and $60 \mathrm{cfu} / \mathrm{g}$ sample) for the $\left(5,20,35\right.$ and $\left.50^{\circ} \mathrm{C}\right)$ temperature treatments, respectively. Again, the maximum TBC value of $140 \mathrm{cfu} / \mathrm{g}$ was found at $20^{\circ} \mathrm{C}$.

It is known that WRC wood is resistant against decay as extractives such as thujaplicins are present. We measured percent DM loss of the materials and found that 0.06-0.26\% of DM was lost for the non-aerobic reactors, as compared to $0.15-0.57 \%$ for the aerobic reactors under different temperatures. Such small degree of DM loss over the storage period compared to those reported for other materials in the literature seems to reaffirm the decay-resistance characteristics of WRC (Wihersaari 2005; Pettersson and Nordfjell 2007; Eriksson and Gustavsson 2010). Therefore, the $\mathrm{CO}_{2}$ emissions observed in this study could be primarily due to microbial respiration rather than decomposition of the biomass.

The $\mathrm{CO}_{2}$ and $\mathrm{CO}$ emissions could have safety and health implications, depending on the duration of exposure. The threshold limit value-time weighted average (TLV-TWA) values for $8 \mathrm{~h}$ exposure to $\mathrm{CO}_{2}$ and $\mathrm{CO}$ are set at 0.5 and 
$0.0025 \%$, respectively. The TLV-STEL (short-term exposure limit) values for 15 min exposure to $\mathrm{CO}_{2}$ and $\mathrm{CO}$ are 3 and $0.01 \%$, respectively. The corresponding concentrations that are deemed "Immediately Dangerous to Life and Health" for $\mathrm{CO}_{2}$ and $\mathrm{CO}$ are 4 and $0.12 \%$, respectively (ACGIH, 2004). According to Fig. 3, the $\mathrm{CO}_{2}$ concentrations after 10 days of storage were greater than $5,000 \mathrm{ppm}$ or $0.5 \%$ (TLV-TWA for $8 \mathrm{~h}$ exposure). Moreover, the $\mathrm{CO}_{2}$ concentrations attained $3 \%$ (TLVSTEL for 15 min exposure) after 5-10 days $\left(20\right.$ and $\left.35^{\circ} \mathrm{C}\right)$ and $25-40$ days $\left(5\right.$ and $45^{\circ} \mathrm{C}$ ). Eventually, after 35 days of storage, the $\mathrm{CO}_{2}$ concentrations were beyond $4 \%$ (immediately dangerous to life and health) for the 5,20 and $35{ }^{\circ} \mathrm{C}$ temperatures. Hence, the $\mathrm{CO}_{2}$ emissions observed from the non-aerobic reactors in this study exceeded these threshold values by a rather large margin.

The levels of oxygen and toxic gases from logs and wood chips stored in confined spaces during sea transportation were studied by Svedberg et al. (2009). The types of wood were pine, spruce, birch and aspen. The materials had been on board for 37-66 h. Various degrees of oxygen depletion and $\mathrm{CO}_{2}$ elevation were observed in the stairway samples from the ships. The mean oxygen level in the cargo was $10 \%$; however, it was depleted to $0 \%$ in some shipments. The reported average concentrations of $\mathrm{CO}_{2}$ and $\mathrm{CO}$ were $7.5 \%$ and $46 \mathrm{ppm}$, respectively. In our experimental study for WRC, the $\mathrm{CO}_{2}$ levels ranged from 2 to $16 \%$ depending on the storage temperature, whereas $\mathrm{CO}$ levels ranged from 200 to $2,800 \mathrm{ppm}$ as temperature varied from 35 to $50{ }^{\circ} \mathrm{C}$.

Besides, we made a comparison of our observed emission factors with those obtained from stored wood pellets (3.7-10\% moisture content, wet basis) under oxygendepleting environment. Kuang et al. (2009a, b) reported the $\mathrm{CO}_{2}$ emission factor to increase from 0.025 to $0.23 \mathrm{~g} / \mathrm{kg}$ $\mathrm{DM}$ as temperature was raised from 10 to $45^{\circ} \mathrm{C}$ after 30 days storage, while the corresponding $\mathrm{CO}$ emission factor increased from 0.001 to $0.058 \mathrm{~g} / \mathrm{kg} \mathrm{DM}$. They concluded that chemical auto-oxidation process could be the dominant mechanism for the gas emissions from wood pellets. The highest $f_{\mathrm{co}_{2}}$ from WRC chips in this study was almost 10 times greater than those derived from wood pellets, whereas $\mathrm{f}_{\mathrm{CO}}$ was similar to those from pellets. When the initial $\mathrm{O}_{2}$ content was high in the reactors, it was possible for the fresh wood chips to release a greater amount of $\mathrm{CO}_{2}$ than the wood pellets due to biological process in addition to chemical oxidation. At the later stage of storage, when anaerobic condition would prevail at $\mathrm{O}_{2}$ content close to zero, the biological process was inhibited so that no more $\mathrm{CO}_{2}$ was generated; thus, the emission factor of $\mathrm{CO}_{2}$ reached the peak value.

Moisture content is a key factor that governs biological reactions. Kuang et al. (2009a) postulated that biological process may contribute to the emissions for moist biomass such as wood chips; our findings from this study confirm their hypothesis. The large differences in $f_{\mathrm{CO}_{2}}$ could be attributed to the much higher moisture content of the fresh wood chips (50\% wet mass basis) with live microbes, whereas most of the microbes should have been killed during pelletization and the pre-pelletization drying process at high temperature.

\section{Gas emissions from sterilized woodchips}

In order to verify the dominance by the biological process for the emission of $\mathrm{CO}_{2}$, another series of experiment was conducted. The WRC woodchips were sterilized in a bench-top steam sterilizer (Sterilemax Series 1277 Table Top Model, Thermo Scientific, USA) at $135{ }^{\circ} \mathrm{C}$ for $15 \mathrm{~min}$ to eliminate the microbes. Steam condition was adjusted to maintain the moisture content of the chips at the same level. After cooling down, $330 \mathrm{~g}$ of steam-sterilized woodchips was loaded into each reactor. The experiment was conducted at temperatures of $5,20,35,45$ and $50{ }^{\circ} \mathrm{C}$.

Results from running the test under non-aerobic condition are shown in Fig. 6. After 60 days storage, the $\mathrm{CO}_{2}$ emission factors for the treated (sterilized) woodchips were lower than those from the untreated woodchips with temperature ranging from 5 to $50{ }^{\circ} \mathrm{C}$ (Fig. 3) by around 4 times. Evidently, the $\mathrm{CO}_{2}$ and $\mathrm{CO}$ emissions were directly proportional to temperature and this phenomenon is typical of chemical reaction. These findings are unlike the unsterilized wood chips, when the 20 and $35{ }^{\circ} \mathrm{C}$ treatments resulted in higher $\mathrm{CO}_{2}$ emission compared with the 5, 45 and $50{ }^{\circ} \mathrm{C}$ treatments. It indicated that biological mechanism was no longer dominant for $\mathrm{CO}_{2}$ emission as the microbes would have been killed by the sterilization process. Thus, the findings from this test series confirmed that biological process could play a leading role in generating $\mathrm{CO}_{2}$ emissions from the stored WRC wood chips.

\section{Characteristics of VOCs}

The components of VOCs and their total concentration were analyzed in this study. A range of chemical compounds were identified from the qualitative GC/MS analysis. Measurements indicated that at all temperatures tested; the VOCs emitted were aromatic compounds, including benzene and its derivatives. Methanol, aldehydes, terpene, acid (including methoxyacetic acid, acetic acid, formic acid and benzoic acid), acetone, hexane, ketone, ethers and esters were found in the gas emissions from the WRC woodchips, similar to other wood products (Leinonen and tutkimuskeskus 2004; Svedberg et al. 2004; Hagström 2008; Arshadi et al. 2009; He et al. 2012). Furan was also detected in the emitted gases, which could be 


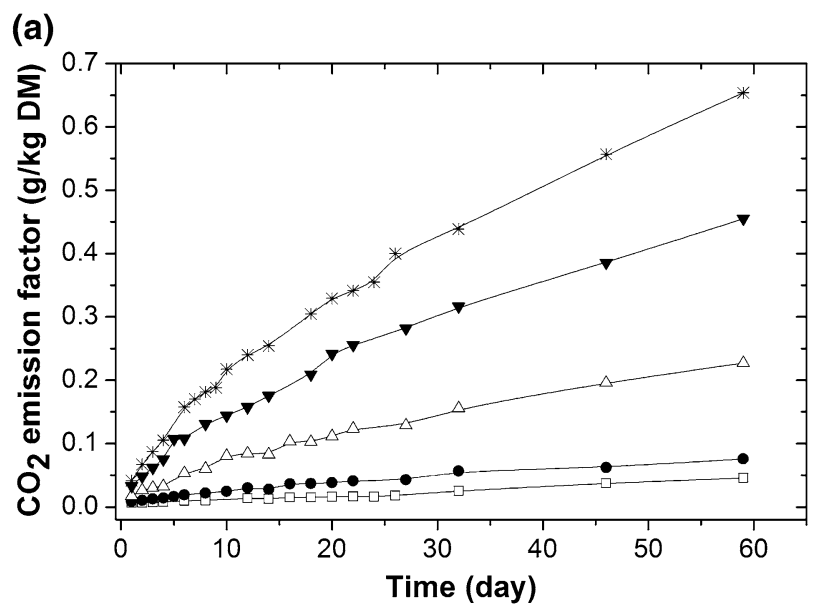

(b)
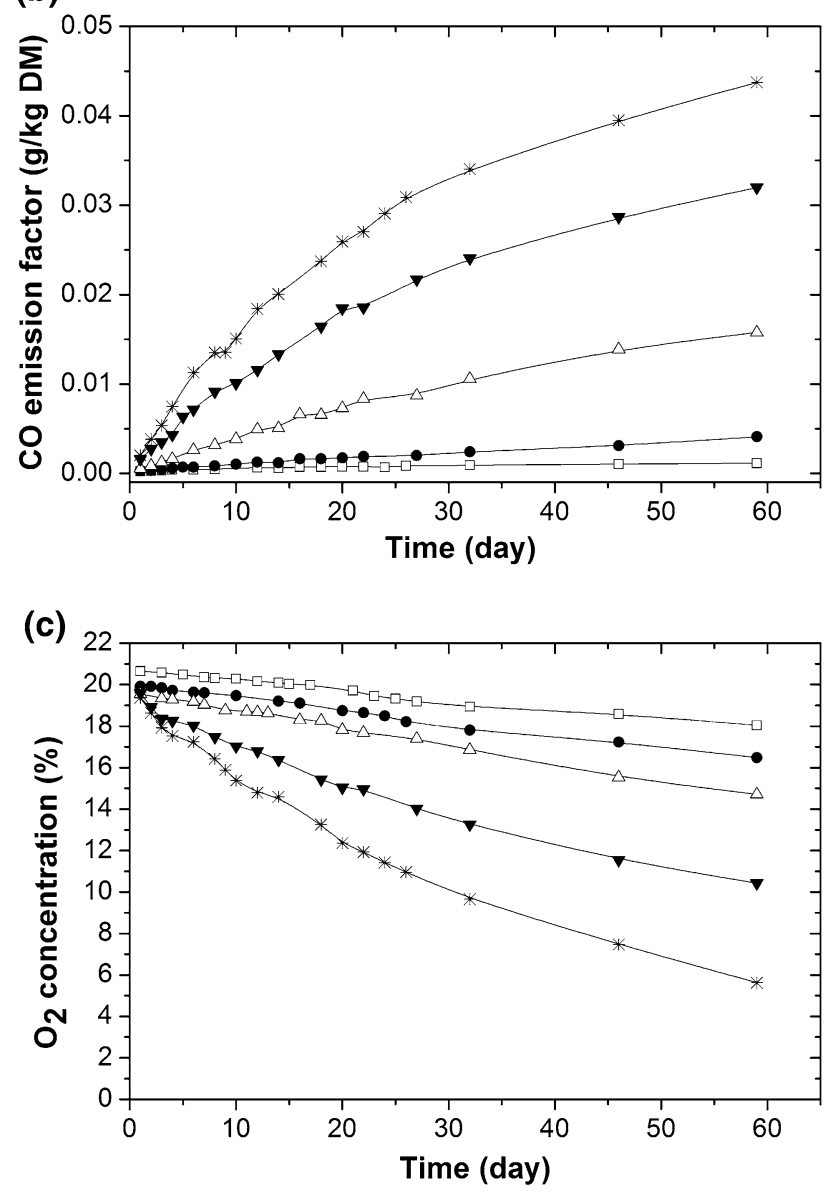

Fig. 6 Gas emission from treated WRC chips under different temperatures (non-aerobic) square $5{ }^{\circ} \mathrm{C}$; circle $20^{\circ} \mathrm{C}$; triangle $35{ }^{\circ} \mathrm{C}$; inverted triangle $45{ }^{\circ} \mathrm{C}$; asterick $50{ }^{\circ} \mathrm{C}$ )

attributed to the uptake of chloride ions in the WRC wood chips during transport in the salty waters of Pacific Ocean. Indole was found to emit from the reactors under high temperatures of 45 and $50{ }^{\circ} \mathrm{C}$. These VOCs could be inhaled by people working near the woodchip storage area, or nearby residents, and causing irritation to the respiratory

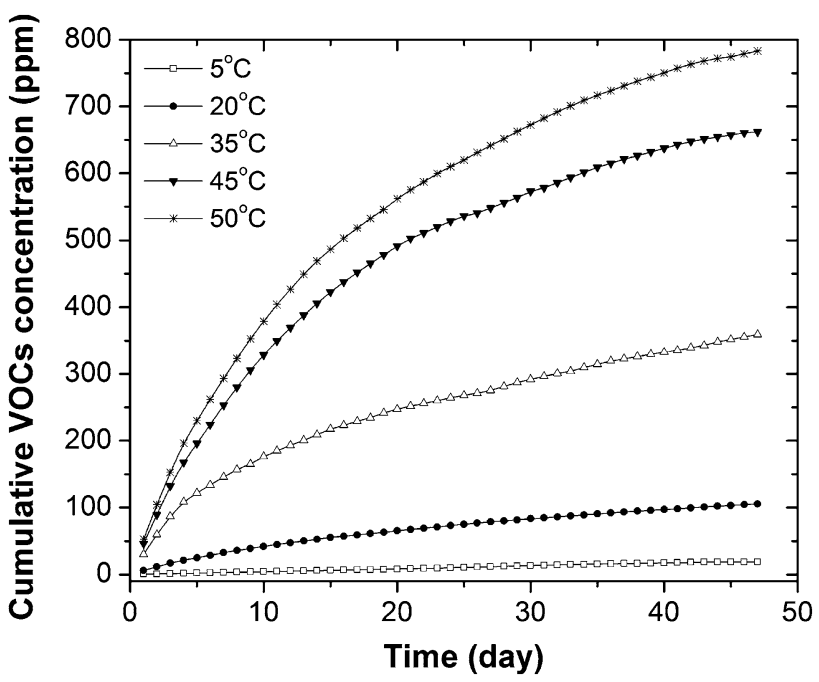

Fig. 7 Cumulative total concentration of VOCs from the aerobic reactors at various temperatures

system. The odorous VOCs such as indole, terpenes, aldehydes and ketones could also induce odor nuisance problems.

Figure 7 illustrates the cumulative total concentrations of VOCs (TVOCs) with time from the aerobic reactors. It can be seen that temperature is positively correlated with TVOC concentration. The initial concentration was less than approximately $1 \mathrm{ppm}$ at $5{ }^{\circ} \mathrm{C}$ but as high as $53 \mathrm{ppm}$ at $50{ }^{\circ} \mathrm{C}$. Temperature can induce the release of VOCs; the results are similar to those reported by other researches (Stahl et al. 2004; Arshadi et al. 2009). The summation of TVOC concentrations over the storage period of 60 days returned values of $20,110,360,660$ and $800 \mathrm{ppm}$ as the temperature increased from 5 to $50{ }^{\circ} \mathrm{C}$. The incremental emission of TVOCs decreased with time, suggesting that the applied heat during storage might reduce the volatiles. Stahl et al. (2004) and Hyttinen et al. (2010) also showed the heat-treated wood had reduced volatile emissions.

The concentrations of TVOC emitted from the nonaerobic reactors at the end of 60 days storage were 11,89 , 237, 429 and $560 \mathrm{ppm}$ for temperature ranging from 5 to $50{ }^{\circ} \mathrm{C}$, respectively. It showed somewhat lower concentrations than those from the aerobic reactors during storage. Taking the total $\mathrm{CO}_{2}$ emissions together with the total TVOC emissions over the entire storage period, a positive correlation between percent DM loss and gas emission was found with a correlation coefficient of 0.92 .

\section{Conclusion}

Gas emissions from stored WRC chips under different storage conditions were studied. Under non-aerobic 
conditions, the emissions of $\mathrm{CO}_{2}$ and $\mathrm{CO}$ increased gradually with time for all temperatures. At higher temperatures, higher $\mathrm{CO}$ emissions were measured, which could be attributed to chemical oxidation mechanism. In contrast, lower emissions of $\mathrm{CO}_{2}$ along with higher $\mathrm{O}_{2}$ concentrations were observed at higher temperatures. At $20{ }^{\circ} \mathrm{C}$, the emission of $\mathrm{CO}_{2}$ was the highest which was followed by $35^{\circ} \mathrm{C}$. After 3 weeks, the emission factor of $\mathrm{CO}_{2}$ reached a plateau of $2.8 \mathrm{~g} / \mathrm{kg} \mathrm{DM}$ (or, $16 \%$ concentration) as oxygen content was depleted to $0 \%$, indicating that the storage environment has turned anaerobic. By comparison, oxygen content was lowered to $10-15 \%$ for other temperatures.

Results further showed that $\mathrm{CO}_{2}$ and $\mathrm{CO}$ emissions from the aerobic reactors exhibited similar trends as the nonaerobic reactors with respect to the effect of temperature. However, total gas emissions were higher from the aerobic reactors than the non-aerobic reactors while oxygen levels were maintained close to $20 \%$ over the same storage period. Biological reaction could be dominant during the storage of wet biomass, leading to the highest level of microbial activity at $20{ }^{\circ} \mathrm{C}$ rather than at higher temperatures. Gas emissions from sterilized woodchips as well as microbial analysis result in terms of total bacteria counts supported the phenomenon of dominance by biological mechanism for $\mathrm{CO}_{2}$ emission.

Qualitative GC/MS analysis indicated that the major VOCs emitted include benzene and its derivatives, methanol, terpenes, aldehydes, acids, alkane, indole, furan, acetone, ethers and esters. The total concentration of VOCs was found to be higher at higher temperatures for both aerobic and non-aerobic storage conditions. The TVOC concentrations from non-aerobic reactors were somewhat lower than the TVOC concentrations from the aerobic reactors over the entire storage period. Taking the total $\mathrm{CO}_{2}$ emissions together with the total TVOC emissions over the entire storage period, a positive correlation between the percent DM loss and gas emission was found. At the end of storage period, percent DM was below $1 \%$ for both the non-aerobic and aerobic reactors, reaffirming the decay-resistance characteristics of WRC.

Overall, the gas emission results from this study reaffirm the importance of ensuring safe and eco-friendly storage conditions for wet woody biomass such as the WRC woodchips, and controlling the emission of odorous VOCs.

Acknowledgments The authors gratefully acknowledge the financial support by the Natural Sciences and Engineering Research Council of Canada (Grant number RGPIN 42377-12), British Columbia Innovation Council/Natural Resources and Applied Sciences Endowment Fund (Grant number NRAS), the U.S. Department of Energy, Office of Biomass Program, and the China Scholarship Council. Thanks are also due to Dr. Karen Bartlett for her assistance with the instrument for total VOC emission analysis.

\section{Appendix}

Mass of materials in the reactor: $M$

Void space in the container: $V$

At $t=0, \mathrm{~N}_{2}$ concentration is $C_{\mathrm{n} 0}$

At time $t$, the $\mathrm{N}_{2}$ concentration is $C_{\mathrm{nt}}$, the volumetric gas concentration is $C_{\mathrm{i}}$, and the gas volume is $V_{\mathrm{t}}$.

Since $\mathrm{N}_{2}$ is an inert gas, which is not consumed or generated, the mass of $\mathrm{N}_{2}$ would remain the same over the entire test.

$$
\begin{aligned}
& V C_{\mathrm{n} 0}=V_{\mathrm{t}} C_{\mathrm{nt}} \\
& o r, V_{\mathrm{t}}=V C_{\mathrm{n} 0} / C_{\mathrm{nt}}
\end{aligned}
$$

Based on Ideal Gas Law, $P V=n R T$, where $R=8.31 \mathrm{~J} /$ mol. $\mathrm{K}$ for each gas species produced, $P C_{\mathrm{i}} V_{\mathrm{t}}=\left(m_{\mathrm{i}} / M_{\mathrm{wt}}\right)$ $R T$

$P C_{\mathrm{i}}\left(V C_{\mathrm{n} 0} / C_{\mathrm{nt}}\right)=\left(f_{\mathrm{i}} M / M_{\mathrm{wt}}\right) R T$.

Hence,

$f_{\mathrm{i}}=\frac{P C_{\mathrm{i}} V M_{\mathrm{wt}} C_{\mathrm{n} 0}}{M R T C_{\mathrm{nt}}}$.

\section{References}

ACGIH (2004) Tlvs and beis: based on the documentation of the threshold limit values for chemical substances and physical agents and biological exposure indices. American Conference of Governmental Industrial Hygienists

Agrios GN (2004) Plant pathology, 5th edn. Academic Press, New York

Arshadi M, Gref R (2005) Emission of volatile organic compounds from softwood pellets during storage. For Prod J 55(12):132-135

Arshadi M, Geladi P, Gref R, Fjallstrom P (2009) Emission of volatile aldehydes and ketones from wood pellets under controlled conditions. Ann Occup Hyg 53(8):797-805

ASABE (2010) Moisture measurement—forage (s358.2). American Society of Agricultural Engineers, St. Joseph

Biomass Technology Group BV (2002) Methane and nitrous oxide emissions from biomass waste stockpiles. Final report for the World Bank PCFplus research program project no. 1050. Washington, p 94

Eriksson L, Gustavsson L (2010) Comparative analysis of wood chips and bundles-costs, carbon dioxide emissions, dry-matter loss and allergic reactions. Biomass Bioenerg 34(1):82-90

Gauthier S, Grass H, Lory M, Krämer T, Thali M, Bartsch C (2012) Lethal carbon monoxide poisoning in wood pellet storeroomstwo cases and a review of the literature. Ann Occup Hyg 56(7):755-763

Gonzalez JS (1997) Growth, properties and uses of western redcedar (thuja plicata donn ex d. Don.). Forintek Canada Corporation. No. SP-37R

Granstrom K, Mansson B (2008) Volatile organic compounds emitted from hardwood drying as a function of processing parameters. Int J Environ Sci Technol 5(2):141-148

Hagström K (2008) Occupational exposure during production of wood pellets in Sweden. Department of Natural Sciences, Örebro University, Doctoral Thesis. ISBN 978-91-7668-571-6 
He X, Lau AK, Sokhansanj S, Lim CJ, Bi XT, Melin S (2012) Dry matter loss in combination with gaseous emissions during the storage of forest residues. Fuel 95:662-664

Health Canada (2001) Hpb methods of microbiological analysis of foods (mfhpb-18). Health Prod Food Branch, Ottawa

Health Canada (2004) Enumeration of yeasts and moulds in foods (mfhpb-22). Health Prod Food Branch, Ottawa

Hellebrand H, Schade G (2008) Carbon monoxide from composting due to thermal oxidation of biomass. J Environ Qual 37(2):592-598

Hyttinen M, Masalin-Weijo M, Kalliokoski P, Pasanen P (2010) Comparison of voc emissions between air-dried and heat-treated norway spruce (picea abies), scots pine (pinus sylvesteris) and european aspen (populus tremula) wood. Atmos Environ 44(38):5028-5033

Johansson A, Rasmuson A (1998) The release of monoterpenes during convective drying of wood chips. Drying Technol 16(7):1395-1428

Koppmann R, Czapiewski KV, Reid J (2005) A review of biomass burning emissions, part i: gaseous emissions of carbon monoxide, methane, volatile organic compounds, and nitrogen containing compounds. Atmos Chem Phys Discuss 5(5):10455-10516

Kuang X, Shankar T, Bi XT, Sokhansanj S, Lim CJ, Melin S (2008) Characterization and kinetics study of off-gas emissions from stored wood pellets. Ann Occup Hyg 52(8):675-683

Kuang X, Shankar T, Bi XT, Lim CJ, Sokhansanj S, Melin S (2009a) Rate and peak concentrations of off-gas emissions in stored wood pellets-sensitivities to temperature, relative humidity, and headspace volume. Ann Occup Hyg 53(8):789-796

Kuang X, Shankar T, Sokhansanj S, Lim CJ, Bi XT, Melin S (2009b) Effects of headspace and oxygen level on off-gas emissions from wood pellets in storage. Ann Occup Hyg 53(8):807-813

Leinonen A, Tutkimuskeskus V (2004) Harvesting technology of forest residues for fuel in the USA and finland. VTT TIEDOTTEITA, Finland

Liu ZM, Daniels C, Morris PI (2010) New method to isolate gammathujaplicin from western red cedar (thuja plicata donn.). J Wood Chem Technol 30(3):299-314
Nakamura A, Miyafuji H, Saka S (2010) Liquefaction behavior of western red cedar and japanese beech in the ionic liquid 1-ethyl3-methylimidazolium chloride. Holzforschung 64(3):289-294

Pettersson M, Nordfjell T (2007) Fuel quality changes during seasonal storage of compacted logging residues and young trees. Biomass Bioenerg 31(11-12):782-792

Ragauskas AJ, Williams CK, Davison BH, Britovsek G, Cairney J, Eckert CA, Frederick WJ, Hallett JP, Leak DJ, Liotta CL (2006) The path forward for biofuels and biomaterials. Science 311(5760):484-489

Rentizelas A, Tolis A, Tatsiopoulos I (2009) Logistics issues of biomass: the storage problem and the multi-biomass supply chain. Renew Sustain Energy Rev 13(4):887-894

Rupar K, Sanati M (2005) The release of terpenes during storage of biomass. Biomass Bioenerg 28(1):29-34

Stahl M, Granstrom K, Berghel J, Renstrom R (2004) Industrial processes for biomass drying and their effects on the quality properties of wood pellets. Biomass Bioenerg 27(6):621-628

Svedberg U, Hogberg H, Hogberg J, Galle B (2004) Emission of hexanal and carbon monoxide from storage of wood pellets, a potential occupational and domestic health hazard. Ann Occup Hyg 48(4):339-349

Svedberg U, Samuelsson J, Melin S (2008) Hazardous off-gassing of carbon monoxide and oxygen depletion during ocean transportation of wood pellets. Ann Occup Hyg 52(4):259-266

Svedberg U, Petrini C, Johanson G (2009) Oxygen depletion and formation of toxic gases following sea transportation of logs and wood chips. Ann Occup Hyg 53(8):779-787

Wihersaari M (2005) Evaluation of greenhouse gas emission risks from storage of wood residue. Biomass Bioenerg 28(5):444-453

Zhang Y, McKechnie J, Cormier D, Lyng R, Mabee W, Ogino A, MacLean HL (2009) Life cycle emissions and cost of producing electricity from coal, natural gas, and wood pellets in ontario, canada. Environ Sci Technol 44(1):538-544

Zhang L, Ninomiya Y, Wang Q, Yamashita T (2011) Influence of woody biomass (cedar chip) addition on the emissions of $\mathrm{pm}_{10}$ from pulverised coal combustion. Fuel 90(1):77-86 